\title{
Theoretical Study of The Chemical Reactivity of A Class of Trivalent Phosphorus Derivatives Towards Polyhaloalkanes: DFT Study.
}

\section{Ali Barhoumi}

Chouaib Doukkali University Faculty of Sciences: Universite Chouaib Doukkali Faculte des Sciences Mohammed El idrissi ( $\square$ m.elidrissi2018@gmail.com )

Sultan Moulay Slimane University Polydisciplinary Faculty of Beni Mellal: Universite Sultan Moulay Slimane Faculte Polydisciplinaire de Beni Mellal https://orcid.org/0000-0002-4712-361X

\section{Abdellah Zeroual}

Chouaib Doukkali University Faculty of Sciences: Universite Chouaib Doukkali Faculte des Sciences

Abdessamad Tounsi

Sultan Moulay Slimane University Polydisciplinary Faculty of Beni Mellal: Universite Sultan Moulay Slimane Faculte Polydisciplinaire de Beni Mellal

\section{Salam Bakkas}

Chouaib Doukkali University: Universite Chouaib Doukkali

\section{Abdeslam El hajbi}

Chouaib Doukkali University: Universite Chouaib Doukkali

\section{Research Article}

Keywords: Trivalent phosphorus derivatives, polyhaloalkanes, DFT/B3LYP/6-311G(d,p), global indices, transition state, thermodynamic properties

Posted Date: April 21st, 2021

DOI: https://doi.org/10.21203/rs.3.rs-393422/v1

License: (c) (i) This work is licensed under a Creative Commons Attribution 4.0 International License. Read Full License 


\title{
Theoretical study of the chemical reactivity of a class of trivalent phosphorus derivatives towards polyhaloalkanes: DFT Study.
}

Ali Barhoumi ${ }^{1,4}$, Mohammed El idrissi ${ }^{2}$, Abdellah Zeroual ${ }^{1}$, Abdessamad Tounsi ${ }^{3}$, Salam Bakkas $^{4}$, Abdeslam El hajbi ${ }^{1}$

\footnotetext{
${ }^{1}$ Molecular Modeling and Spectroscopy Research Team, Faculty of Science, Chouaïb Doukkali University, P.O. Box 20, 24000 El Jadida, Morocco.

${ }^{2}$ Laboratory of Chemical Processes and Applied Materials, Sultan Moulay Slimane University, Polydisciplinary Faculty of Beni-Mellal, Morocco.

${ }^{3}$ Research Team in Applied Chemistry and Modeling ERCAM, Faculty Polydisciplinary Beni Mellal, Morocco.

${ }^{4}$ Laboratory of Organic, Bio-organic and Environmental Chemistry, Department of Chemistry, Faculty of Science, Chouaïb Doukkali University, BP 20, 24000 El Jadida, Morocco.

*E-mail address of the corresponding author: m.elidrissi2018@gmail.com
}

\begin{abstract}
In the current work, the chemical reactivity of some trivalent phosphorus derivatives $\mathrm{R}_{2} \mathrm{PR}^{\prime}$ towards polyhaloalkanes $\mathrm{CCl}_{3} \mathrm{POR}_{2}{ }_{2}$ was studied by the quantum method DFT/B3LYP/6-311G (d,p). The introduction of substituents for the trivalent phosphorus derivative and polyhaloalkane allowed us to have more information on these reactions. On the one hand, the calculation of reactivity indices derived from the DFT/B3LYP/6-311G(d,p)

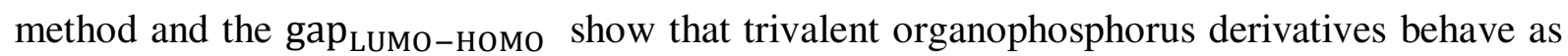
nucleophiles, while polyhaloalkanes act as electrophiles. On the other hand, the calculation of the activation barrier and the determination of the free enthalpy variation prove that the kinetic and thermodynamic products of these reactions result from the nucleophilic attack of the phosphorus atom on the chlorine halogen. All these theoretical predictions are in very good agreement with the experimental results.
\end{abstract}

Keywords: Trivalent phosphorus derivatives, polyhaloalkanes, DFT/B3LYP/6-311G(d,p), global indices, transition state, thermodynamic properties.

\section{Introduction}

Most polyhalomethanes such as tetrachloromethane $\mathrm{CCl}_{4}$ [1], chloroform $\mathrm{CHCl}_{3}[2,3]$, diethyl trichloromethyl phosphonate $\mathrm{CCl}_{3} \mathrm{PO}(\mathrm{OEt})_{2}$ [4,5] and trichloromethylphosphine oxide $\mathrm{CCl}_{3} \mathrm{PO}(\mathrm{Ph})_{2}$ [6] react with trialkylphosphites through the participation of a single halogen atom. However, dichloromethyl ether [7] and N-(trichloromethyl)-dialkylamine [8] which are highly electrophilic polyhaloalkanes can substitute two or even three of their halogen atoms with dialkylphosphonyl groups. The introduction of an electron-withdrawing group strongly activates the halogen in position as in the case of trichloroacétonitrille $\left(\mathrm{CCl}_{3}-\mathrm{CN}\right)$ which engages the three chlorine atoms by reacting with phosphites according to Figure 1 [9].

Following this scheme, Sagina and Kukhar [9] expected trichloromethyl phosphonate 2 to act in the same way as trichloroacetonitrile despite the low electron acceptor power of the dialkylphosphonyl group compared to the nitrile function. 
The reaction carried out according to Figure 2, at temperatures between $120^{\circ} \mathrm{C}$ and $130^{\circ} \mathrm{C}$ in the absence of solvent and catalyst, allowed the synthesis of bisphosphonate 3 with a yield of $82 \%$ from equivalent proportions of $(\mathrm{RO})_{3} \mathrm{P}$ and $\mathrm{CCl}_{3} \mathrm{PO}(\mathrm{OR})_{2}$. The dichloromethylene bisphosphonate 3 thus obtained was only identified by infrared spectroscopy.

Furthermore, Sagina and Kukhar [10] have shown that bisphosphonate 3 is also obtained by reacting one mole of $\mathrm{CCl}_{4}$ and two moles of phosphite (RO) ${ }_{3} \mathrm{P}$ according to Figure 3. Phosphonate 2 is produced from phosphite (RO) ${ }_{3} \mathrm{P}$ and excess tetrachloromethane. The formation of dichloromethylene bisphosphonate via an SN2 nucleophilic attack on carbon excluding the possibility of a radical mechanism has been proposed [9].

Bakkas and collaborators [11-13] resumed the experimental study of reactions 1a and 2a since the presence of bisphosphonate 3 has never been proven before in the reaction of $\mathrm{CCl}_{4}$ and (EtO) $)_{3} \mathrm{P}$. According to Figure 4, they showed that: i) among other phosphorus compounds, the phosphonate $\mathrm{EtCCl}_{2} \mathrm{P}(\mathrm{OEt})_{2}$ is obtained rather than bisphosphonate 3, ii) bisphosphonate 3 or its derivatives are obtained by a radical mechanism when $\mathbf{1 a}$ and $\mathbf{2 a}$ react under UV light.

It was concluded that the thermal reaction of triethylphosphite $\mathbf{1 a}$ with diethyltrichloromethyl phosphonate $\mathbf{2 a}$ takes place according to a nucleophilic attack of 1a on one of the chlorine atoms of $\mathbf{2 a}$. This has been verified at room temperature by reacting [9] the polyhaloalkane 2a with the more reactive phosphinite $(\mathrm{Ph})_{2} \mathrm{POCH}_{3}$ than the phosphite $(\mathrm{EtO})_{3} \mathrm{P}$.

In the current study, we will perform a theoretical study using the DFT/B3LYP/6$311 \mathrm{G}(\mathrm{d}, \mathrm{p})$ method, of the reaction of $\mathrm{CCl}_{3} \mathrm{POR}_{2}{ }_{2}$ with $\mathrm{R}_{2} \mathrm{PR}^{\prime}$ in order to specify its reaction mechanism. This consists in checking Figure 4 which supposes that the phosphorus atom, considered as a nucleophilic center, will attack the carbon $\left(\mathrm{A}_{\mathrm{C}}\right)$ or the chlorine $\left(\mathrm{A}_{\mathrm{Cl}}\right)$ of the polyhaloalkane $\mathrm{CCl}_{3} \mathrm{POR}_{2}{ }_{2} 2$ assumed to be electrophilic centers.

\section{Calculation details}

The quantum calculations were performed using Gaussian 09 [14]. The equilibrium geometries were visualized using the GaussView program which can generate a threedimensional arrangement serving as a starting point for geometry optimization at the quantum level. The geometry of neutral systems has been maintained for cationic and anionic systems used for local indices calculations. We used the Density Functional Theory (DFT), an approach that is very widespread today. A double choice is necessary to perform the calculations: the type of functional and the atomic orbital base. The B3LYP/6-311G(d,p) $[15,16]$ level has been chosen here because of its satisfactory quality/cost ratio considering the size of our systems.

The localization of the transition states obtained by the B3LYP/6-311G $(\mathrm{d}, \mathrm{p})$ method was confirmed by the presence of one and only one imaginary frequency in the Hessian matrix. The IRC (Intrinsic Reaction Coordinate) calculation [17] was performed to show 
whether the transition state is well related to the two minima (reagents and products). Furthermore, enthalpies, entropies and free energies values were determined using standard statistical thermodynamics through calculation of the vibration frequencies [16].

\section{Results and discussion}

\subsection{Study of structural and electronic properties}

\subsubsection{Geometrical parameters of reagents $\mathrm{CCl}_{3} \mathrm{PO}(\mathrm{OEt})_{2}$ and $\mathrm{CCl}_{3} \mathrm{PO}(\mathrm{Ph})_{2}$}

Figure 5 present the optimized geometries obtained by the B3LYP functional and the base $6-311 \mathrm{G}(\mathrm{d}, \mathrm{p})$ and the numbering of the atoms of the most stable conformation of polyhaloalkanes $\mathrm{CCl}_{3} \mathrm{PO}(\mathrm{OEt})_{2}$ and $\mathrm{CCl}_{3} \mathrm{PO}(\mathrm{Ph})_{2}$.

The lengths, energies and angles of the bonds involved in the studied reactions were determined from these optimized structures. There values are summarized in Table 1.

Results obtained show that the reactivity of the chlorine atoms of the two polyhaloalkanes $\left[\mathrm{CCl}_{3} \mathrm{PO}(\mathrm{OEt})_{2}\right.$ and $\left.\mathrm{CCl}_{3} \mathrm{PO}(\mathrm{Ph})_{2}\right]$ do not have the same strength towards the most reactive site of the organophosphorus $\left[\mathrm{P}(\mathrm{OEt})_{3}\right.$ and $\left.(\mathrm{Ph})_{2} \mathrm{POCH}_{3}\right]$.

\subsubsection{Electronic properties: partial atomic charges}

The use of Mulliken's population analysis (MPA) [18] allows to determine Mulliken's charges which help to estimate partial atomic charges using the DFT/B3LYP/6-311G(d,p) calculation method. Atomic charges were also determined using natural population analysis (NPA) [19] at the B3LYP/6-311G(d,p) level.

The results obtained for these electronic parameters are summarized in Table 2. Examination of the distribution of net charges at the most reactive sites of polyhalogénoalcanes $\left[\mathrm{CCl}_{3} \mathrm{PO}(\mathrm{OEt})_{2}\right.$ and $\left.\mathrm{CCl}_{3} \mathrm{PO}(\mathrm{Ph})_{2}\right]$, allow us to state the following findings: i) due to the negativity of its net charge the carbon atom is an electron-rich site, ii) since the chemical environment of the three chlorine atoms are different then their positive charges are unevenly distributed and are, therefore, electron deficient sites.

According to these results we can consider carbon atom as a nucleophilic site whereas the chlorine halogen is more active towards a nucleophilic attack.

\subsubsection{Frontier Orbital Analysis}

The concept of Frontier Molecular Orbital (FMO) allows analyzing the reactivity of molecules in terms of interactions of the molecular orbitals of the reagents by considering only the most important interactions [20]. In the case of the reaction of trivalent phosphorus derivatives $\left[\mathrm{P}(\mathrm{OEt})_{3}\right.$ and $\left.(\mathrm{Ph})_{2} \mathrm{POCH}_{3}\right]$ with polyhaloalkanes $\left[\mathrm{CCl}_{3} \mathrm{PO}(\mathrm{OEt})_{2}\right]$ and $\left[\mathrm{CCl}_{3} \mathrm{PO}(\mathrm{Ph})_{2}\right]$, the charge transfer that takes place near the transition state mainly involves electrons from the nucleophile's Highest Occupied Molecular Orbital (HOMO) to the electrophilic's Lowest Vacant Molecular Orbital (LUMO). As a result, the electron density 
associated with these electrons should explain the reactivity and selectivity of this reaction. The HOMO and LUMO orbitals can inform us about the mode of interaction between molecular entities.

Indeed, the HOMO acts as electron donor and the LUMO acts as electron acceptor.

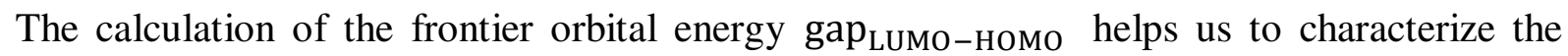
chemical reactivity and the kinetic stability of the molecule. It is known that a molecule with a small energy difference (gap) is polarizable and generally associated with high reactivity and low kinetic stability and is called a soft molecule [21].

From the values of the energies of the HOMO and LUMO molecular orbital boundaries determined by the DFT/B3LYP/6-311G(d,p) method, we have calculated the LUMO-HOMO energy difference for the two possible combinations of the studied system, the classification of the values of which is reported in Table 3 in decreasing order of magnitude.

As shown in Figure 6, the orbital diagram gives a good qualitative indication of the reactivity of our system. It can be seen that the main interaction is between the LUMO of polyhaloalkanes $\left[\mathrm{CCl}_{3} \mathrm{PO}(\mathrm{OEt})_{2}, \mathrm{CCl}_{3} \mathrm{PO}(\mathrm{Ph})_{2}\right]$ and the $\mathrm{HOMO}$ of organophosphorus compounds $\left[\mathrm{P}(\mathrm{OEt})_{3}\right.$ and $\left.(\mathrm{Ph})_{2} \mathrm{POCH}_{3}\right]$.

Table 3 shows that the energy difference $E_{\text {LUMO }}-E_{\text {Hомо }}$ is smaller in the case of the reaction of diethyl trichloromethyl phosphonate $\mathrm{CCl}_{3} \mathrm{PO}(\mathrm{OEt})_{2}$ with diphenylmethyl phosphinite $(\mathrm{Ph})_{2} \mathrm{POCH}_{3}$ than with triethyl phosphite 1a. This explains the high reactivity of phosphinite $(\mathrm{Ph})_{2} \mathrm{POCH}_{3}$ with phosphite $(\mathrm{EtO})_{3} \mathrm{P}$ with diethyl trichloromethyl phosphonate $\mathrm{CCl}_{3} \mathrm{PO}(\mathrm{OEt})_{2}$. We note that this reactivity increases with the substitution of the ethoxy group $(-\mathrm{OEt})$ by a phenyl group $(-\mathrm{Ph})$ which reduces the energy gap between the frontier orbitals.

The results presented in Figure 7 show that the molecule $\mathrm{CCl}_{3} \mathrm{PO}(\mathrm{Ph})_{2}$ has the lowest energy gap between the LUMO and HOMO orbital $(5.706 \mathrm{eV})$, justifying its high electroacceptance power. Moreover, $(\mathrm{Ph})_{2} \mathrm{POCH}_{3}$ molecule has the smallest energy gap gap $_{\text {LUMо-номо }}(5.232 \mathrm{eV})$ compared to $(\mathrm{EtO})_{3} \mathrm{P}$ molecule, cofirming its higher electrondonor power with easy transfer of electrons from HOMO to the higher orbitals.

The study of the localization of the molecular orbital frontiers of the reagents studied and their energetic gaps illustrated in Figure 8 allows concluding that the HOMO orbital is localized on the phosphorus atom whereas the LUMO is confined to the chlorine atom. The latter is essentially the seat of nucleophilic attack of the phosphorus compounds $\mathrm{P}(\mathrm{OEt})_{3}$ and $(\mathrm{Ph})_{2} \mathrm{POCH}_{3}$. For the two modes of attack $\left(\mathrm{A}_{\mathrm{C}}\right.$ et $\left.\mathrm{A}_{\mathrm{Cl}}\right)$, this analysis of the reaction correctly explains the regioselectivity observed experimentally [11-13] as well as the good concordance with the values of the free enthalpy variation $\Delta \mathrm{G}_{\mathrm{r}}$.

\subsection{Analysis of the overall properties of the reagents and prediction of the nature of the reaction mechanism}


To clarify the character (electrophilic or nucleophilic) of the reagents studied, the DFT/B3LYP/6-311G(d,p) method was used to calculate the gap energies HOMO/LUMO for the two possible combinations, the results obtained are summarized in Table 4.

Results clearly show that the gap energies corresponding to the HOMO combination of trivalent phosphorus derivatives $\left[(\mathrm{EtO})_{3} \mathrm{P}\right.$ and $\left.(\mathrm{Ph})_{2} \mathrm{POCH}_{3}\right]$, the LUMO of the polyhaloalkanes $\left[\mathrm{CCl}_{3} \mathrm{PO}(\mathrm{OEt})_{2}\right.$ and $\left.\mathrm{CCl}_{3} \mathrm{PO}(\mathrm{Ph})_{2}\right]$ is lower than that corresponding to the HOMO combination of $\left[\mathrm{CCl}_{3} \mathrm{PO}(\mathrm{OEt})_{2}\right.$ and $\left.\mathrm{CCl}_{3} \mathrm{PO}(\mathrm{Ph})_{2}\right]$, and the LUMO of $\left[(\mathrm{EtO})_{3} \mathrm{P}\right.$ and $\left.(\mathrm{Ph})_{2} \mathrm{POCH}_{3}\right]$. This proves that both trivalent phosphorus derivatives act as electron donors and polyhaloalkanes act as electron acceptors.

Global reactivity indices are an efficient tool for the analysis and prediction of the polar or non-polar character of such reactions [22]. The Density Functional Theory (DFT) is currently a real source of chemical concepts such as electronic chemical potential $\mu$ and hardness $\eta$. From these two global descriptors, other indices such as the global softness $S$ or the global electrophilic index $\omega$ can be evaluated. These indices are calculated from the energies of the lowest vacant and highest occupied Kohn-Sham orbitals. It has been shown that the nucleophilicity of a molecule can be related to its ability to neglect its electron density [23]. The nucleophilicity indice $\mathrm{N}$ can be calculated by equation [22].

$$
\mathbf{N}=\mathbf{E}_{\text {LUMo(Nu) }}-\mathbf{E}_{\text {Homo(TCE) }}
$$

- $\mathrm{E}_{\text {HOMO(TCE) }}$ is the HOMO energy of tetracyanoethylene (TCE).

- $\mathrm{E}_{\mathrm{LUMO}(\mathrm{Nu})}$ is the LUMO energy of the nucleophile.

According to results presented in Table 5, the two trivalent phosphorus derivatives have the lowest electrophilicity index $\left[\omega_{(\mathrm{EtO})_{3} \mathrm{P}}=0.640 \mathrm{eV}\right.$ and $\left.\omega_{(\mathrm{Ph})_{2} \mathrm{POCH}_{3}}=1.180 \mathrm{eV}\right]$ compared to polyhaloalkanes $\left[\left(\omega_{\mathrm{CCl}_{3} \mathrm{PO}(\mathrm{OEt})_{2}}=1.727 \mathrm{eV}\right.\right.$ and $\left.\left.\omega_{\mathrm{CCl}_{3} \mathrm{PO}(\mathrm{Ph})_{2}}=1.881 \mathrm{eV}\right)\right]$, and the highest nucleophilicity index $\left[\left(\mathrm{N}_{(\mathrm{EtO})_{3} \mathrm{P}}=2.428 \mathrm{eV}\right.\right.$ and $\left.\left.\mathrm{N}_{(\mathrm{Ph})_{2} \mathrm{POCH}_{3}}=3.237 \mathrm{eV}\right)\right]$. In addition, the electronic chemical potential of the reagents: (EtO $)_{3} \mathrm{P}$ and $(\mathrm{Ph})_{2} \mathrm{POCH}_{3}$ is at a higher energy level than polyhalogénoalcanes $\mathrm{CCl}_{3} \mathrm{PO}(\mathrm{OEt})_{2}$ and $\mathrm{CCl}_{3} \mathrm{PO}(\mathrm{Ph})_{2}$.

In conclusion, the three theoretical approaches (Gaps HOMO/LUMO, the values of the electronic chemical potentials and the values of the electrophilic (nucleophilic) indices) show that the two polyhaloalkanes act as electrophiles (electron acceptor) while the trivalent phosphorus compounds act as nucleophiles (electron donor).

The difference in electrophilicity $(\Delta \omega)$ between the electrophile and the nucleophile is high in the case of triéthylphosphite (EtO) ${ }_{3} \mathrm{P}$. It is also observed that the nucleophilic character is increased by the presence of substituents $(-\mathrm{Ph})$, this shows that the reaction of diethyltrichloromethylphosphonate $\mathrm{CCl}_{3} \mathrm{PO}(\mathrm{OEt})_{2}$ with $\mathrm{POCH}_{3}$ is more favorable than with (EtO) ${ }_{3} \mathrm{P}$.

\subsection{Analysis of local properties}


In order to differentiate the reactivity of the atoms forming a molecule, the local indices in this case the Parr functions $\operatorname{Parr}^{+}(\mathrm{r}) / \mathrm{Parr}^{-}(\mathrm{r})$ were calculated. Table 6 summarizes the values of the local descriptors of reactivity obtained by the method DFT/B3LYP/6-311G(d,p). According to the results obtained, the most favored electrophilic-nucleophilic interaction is between the carbon atom of diethyltrichloromethyl phosphonate $\mathrm{CCl}_{3} \mathrm{PO}(\mathrm{OEt})_{2}$ and the chlorine halogen of trichloromethyl phosphine oxide $\mathrm{CCl}_{3} \mathrm{PO}(\mathrm{Ph})_{2}$ and the phosphorus atom which acts as nucleophilic site of trivalent phosphorus derivatives.

\subsection{Thermodynamic study}

The reaction of diethyltrichloromethyl phosphonate $\mathrm{CCl}_{3} \mathrm{PO}(\mathrm{OEt})_{2}$ with phosphorus compounds $\left[\mathrm{P}(\mathrm{OEt})_{3}\right.$ and $\left.(\mathrm{Ph})_{2} \mathrm{POCH}_{3}\right]$ and the reaction of trichloromethyl phosphine oxide $\mathrm{CCl}_{3} \mathrm{PO}(\mathrm{Ph})_{2}$ with triéthylphosphite $\mathrm{P}(\mathrm{OEt})_{3}$ were studied according to Figure 1 . Using the calculation method DFT/B3LYP/6-311G(d,p), we have calculated and reported in Table 7 the variations in reaction energy $\Delta \mathrm{E}_{\mathrm{r}}$, the variations in reaction enthalpy $\Delta \mathrm{H}_{\mathrm{r}}$ and the variations in free reaction enthalpy $\Delta \mathrm{G}_{\mathrm{r}}$ which correspond to the formation reactions of the products $\mathrm{P}_{\mathrm{C}}$ and $\mathrm{P}_{\mathrm{Cl}}$. Our ultimate goal is to understand the effect of substitution of the ethoxy $(-\mathrm{OEt})$ group by a phenyl $(-\mathrm{Ph})$ group on the reactivity of our systems.

Table 7 shows that the negative values of the free enthalpy variations $\Delta \mathrm{G}_{\mathrm{r}}$ prove that these reactions are possible and thermodynamically favored. On the other hand, the absolute values of the free enthalpy of reaction variation $\Delta \mathrm{G}_{\mathrm{r}}$ that correspond to the formation reactions of $\mathrm{P}_{\mathrm{Cl}}$ compounds from the attack on the chlorine halogen are higher than these of the free enthalpy of reaction variation that correspond to the formation reactions of $\mathrm{P}_{\mathrm{C}}$ compounds from the attack on the carbon $\mathrm{C}$ atom. This result shows that $\mathrm{P}_{\mathrm{Cl}}$ compounds are more thermodynamically stable than $\mathrm{P}_{\mathrm{C}}$ compounds which indicate that the attack on the chlorine atom is the most favorable. Moreover, we noticed that the reaction leading to $\mathrm{P}_{\mathrm{Cl}(1 \mathrm{~b}-2 \mathrm{a})}$ is more favored thermodynamically than the other reactions, since we found a higher absolute value of free enthalpy of reaction. Consequently, the substitution of the ethoxy (-OEt) group by a phenyl $(-\mathrm{Ph})$ group favors the attack on the chlorine atom.

Results also show that the values of $\Delta \mathrm{H}_{\mathrm{r}}$ and $\Delta \mathrm{G}_{\mathrm{r}}$ of the formation reactions of the compounds $\mathrm{P}_{\mathrm{C}}$ and $\mathrm{P}_{\mathrm{Cl}}$ are negative. Therefore, they are exothermic.

We also noted that the absolute values of $\Delta \mathbf{E}_{\mathbf{r}}$, which correspond to the formation reactions of the compounds $\mathrm{P}_{\mathrm{Cl}(1 \mathrm{a}-2 \mathrm{a})}, \mathrm{P}_{\mathrm{Cl}(1 \mathrm{a}-2 \mathrm{~b})}$ and $\mathrm{P}_{\mathrm{Cl}(1 \mathrm{~b}-2 \mathrm{a})}$, are more important than

those of the formation reactions of compounds. $\mathrm{P}_{\mathrm{C}(1 \mathrm{a}-2 \mathrm{a})}, \mathrm{P}_{\mathrm{C}(1 \mathrm{a}-2 \mathrm{~b})}$ et $\mathrm{P}_{\mathrm{C}(1 \mathrm{~b}-2 \mathrm{a}) \text {. This }}$ confirms again that the most favorable site of attack is the chlorine atom.

We can conclude from this theoretical study that the two nucleophilic modes of attack $\left(\mathrm{A}_{\mathrm{C}}\right.$ et $\left.\mathrm{A}_{\mathrm{Cl}}\right)$ of phosphinite $(\mathrm{Ph})_{2} \mathrm{POCH}_{3}$ on diethyltrichloromethyl phosphonate $\mathrm{CCl}_{3} \mathrm{PO}(\mathrm{OEt})_{2}$, and phosphite $(\mathrm{EtO})_{3} \mathrm{P}$ on both electrophiles $\mathrm{CCl}_{3} \mathrm{PO}(\mathrm{OEt})_{2}$ and $\mathrm{CCl}_{3} \mathrm{PO}(\mathrm{Ph})_{2}$ are thermodynamically possible and the products from the attack on the chlorine atom are thermodynamically more favored.

\subsection{Kinetic study}




\subsubsection{Transition state and activation barrier}

Transition state theory (TST) will obviously be used to predict the experimentally observed regioselectivity. We remember that according to this theory, the passage from reagents (initial state) to products (final state) requires the passage through a transition state (intermediate state).

In order to highlight the type of nucleophilic attack of the phosphorus atom of organophosphorus compounds $(\mathrm{EtO})_{3} \mathrm{P}$ and $(\mathrm{Ph})_{2} \mathrm{POCH}_{3}$ on the most electrophilic center of polyhaloalkanes $\mathrm{CCl}_{3} \mathrm{PO}(\mathrm{OEt})_{2}$ and $\mathrm{CCl}_{3} \mathrm{PO}(\mathrm{Ph})_{2}\left(\mathrm{~A}_{\mathrm{C}}\right.$ et $\left.\mathrm{A}_{\mathrm{Cl}}\right)$, the release of an activation barrier is necessary to reach the final state. The transition states (TS), corresponding to the two attack modes $A_{C}$ and $A_{C l}$, have been located at the level of calculation B3LYP/6$311 \mathrm{G}(\mathrm{d}, \mathrm{p})$ whose results are summarized in Table 8 . These TSs were confirmed by the presence of one and only one imaginary frequency in the Hessian matrix.

The potential energy that depends on the geometry of a system, i.e. the spatial coordinates, has a surface corresponding to the two modes of attack $\left(A_{C}\right.$ et $\left.A_{C l}\right)$. As shown in Figure 4 , this potential energy surface shows that the value of the energy of the transition state corresponding to the attack on the chlorine atom $\mathrm{TS}_{\mathrm{Cl}}$ is below that of the energy of the transition state corresponding to the attack on carbon $\mathrm{TS}_{\mathrm{C}}$. Therefore, the attack on the chlorine halogen is kinetically more favored than the attack on the carbon atom.

In this part of our work we have shown that the attack on the chlorine $\mathrm{A}_{\mathrm{Cl}}$ atom is kinetically more favorable considering the very high value of the ratio of the velocity constants of the two nucleophilic attack modes $\left(\mathrm{K}_{\mathrm{Cl}} / \mathrm{K}_{\mathrm{C}}\right)$.

\subsubsection{Structural study of transition states}

The structures optimized by the DFT/B3LYP/6-311G(d) method, p) the TS (transition state) states of the reaction of diethyltrichloromethylphosphonate $\mathrm{CCl}_{3} \mathrm{PO}(\mathrm{OEt})_{2}$ with phosphorus compounds $\left[\mathrm{P}(\mathrm{OEt})_{3}\right.$ and $\left.(\mathrm{Ph})_{2} \mathrm{POCH}_{3}\right]$ and the reaction of trichloromethyl phosphine oxide $\mathrm{CCl}_{3} \mathrm{PO}(\mathrm{Ph})_{2}$ with triéthyl phosphate $\mathrm{P}(\mathrm{OEt})_{3}$ are presented in Figure 9 . The analysis of the results obtained shows that the structure of the transition state associated with the $A_{C}$ attack mode is less stable than that associated with the $A_{C l}$ attack mode. Phosphite is therefore more reactive with chlorine halogen than carbon atom because the length of $\mathrm{P}-$ $\mathrm{CCl}_{2}$ bond is less than that of $\mathrm{P}-\mathrm{Cl}$ one in the transition state.

\subsubsection{Determination of the reaction path}

The evolution of the molecular system along the reaction path between diphenylmethyl phosphinite $(\mathrm{Ph})_{2} \mathrm{POCH}_{3}$ and diethyltrichloromethyl phosphonate $\mathrm{CCl}_{3} \mathrm{PO}(\mathrm{OEt})_{2}$ and between the triéthylphosphite $(\mathrm{EtO})_{3} \mathrm{P}$ and the polyhaloalkanes $\mathrm{CCl}_{3} \mathrm{PO}(\mathrm{OEt})_{2}$ and $\mathrm{CCl}_{3} \mathrm{PO}(\mathrm{Ph})_{2}$ has been studied to ensure that the transition states determined are correct. The Intrinsic Reaction Coordinate (IRC) calculation shown in Figure 10 should ensure that the transition state is related to the reagent and product minima. 


\section{Conclusion}

The calculations of the global indices and the gap LUMO-HOMO $_{\text {by the quantum method }}$ DFT/B3LYP/6-311G(d,p), show that (EtO) $)_{3} \mathrm{P}$ and $(\mathrm{Ph})_{2} \mathrm{POCH}_{3}$ reagents behave of nucleophiles and that the polyhalogénoalcanes $\mathrm{CCl}_{3} \mathrm{PO}(\mathrm{OEt})_{2}$ and $\mathrm{CCl}_{3} \mathrm{PO}(\mathrm{Ph})_{2}$ act as electrophiles.

Using population analysis (MPA) and (NPA), the calculation of partial atomic charges shows that the chlorine halogen is an electrophilic center. It is reminded that the calculation of net charges provided us with good predictions. Nevertheless, it is known in the literature that the calculation of net charges is not considered to be a sufficient descriptor for the prediction of attack sites. To overcome this problem, Parr functions were calculated using population analysis (NPA). The results thus obtained show that the chlorine halogen of $\mathrm{CCl}_{3} \mathrm{PO}(\mathrm{Ph})_{2}$ and the carbon atom of $\mathrm{CCl}_{3} \mathrm{PO}(\mathrm{OEt})_{2}$ should behave as the most reactive sites against nucleophilic attack and the phosphorus atom of trivalent phosphorus derivatives should act as the most nucleophilic site.

The thermodynamic and kinetic studies show that the stable products are those obtained from the attack on the chlorine halogen. The substitution of the ethoxy $(-\mathrm{OEt})$ group by a phenyl $(-\mathrm{Ph})$ group favors the attack on the chlorine atom.

Acknowledgments The authors would like to thank Abdeslam El hajbi for reading the paper.

Declarations Funding The authors received no specific funding for this work.

Conflicts of interest/Competing interests The authors declare that they have no conflict of interest and nocompeting interests exist.

Ethics approval The manuscript is prepared in compliance with the Ethics in Publishing Policy as described in the Guide for Authors.

Consent to participate The manuscript is approved by all authors for publication.

Consent for publication The consent for publication was obtained fromall participants.

Availability of data and material All data generated or analyzed during this study are included in this published article.

Code availability The calculations were performed using: Gaussian 09W, GaussView 5.0 provided by Gaussian 09 and GaussView.05.

Authors' contributions Ali Barhoumi, Mohammed El idrissi and Abdessamad Tounsi: Article writing Salam Bakkas and Abdeslam El hajbi: Directing. Discussion; Mohammed El idrissi, Abdellah Zeroual Final review and editing. 


\section{References}

[1] A. Barhoumi, A. Matine, A. Zeroual, A. Moubarik, S. Bakkas, A. El Hajbi, M. El idrissi. (2020). "Study of the two nucleophilic attack modes $\mathrm{A}_{\mathrm{C}}$ and $\mathrm{A}_{\mathrm{Cl}}$ the reaction between triethylphosphite and tetrachloromethane: DFT Analysis," RHAZES: Green and Applied Chemistry. Vol. 9, no. 2605-6895, pp. 47-55.

[2] Cadogan, J. I. G.; Mackie, R. K. (1974). "Tervalent phosphorus compounds in organic synthesis," vol. 3, no.1, pp. 87-90. https://doi.org/10.1039/cs9740300087

[3]A. J. Burn, J. I. G. Cadogan, P. J. Bunyan, (1964). "The Reaction of Triethyl Pitosphite with Chloroform,". J. Chem. Soc. Vol. 840, no. 4369, pp. 69.

[4] A. Barhoumi, M. El idrissi, A. Zeroual, S. Bakkas, A. El Hajbi, A. Tounsi.(2019). "Theoretical Study of the Regioselectivity of the Reaction Between Diethyl(Trichloromethy1)Phosphonateand Triethylphosphite Using the DFT Method". Euro Rev.of Chem Research, Vol.6 no.1 pp: 3-11. https://doi.org/10.13187/ercr.2019.1.3

[5]A. Barhoumi, M. El Idrissi, S. Bakkas, A. Zeroual, A. Tounsi, A. El Hajbi, (2020). “A DFT study of the mechanism and regioselectivity of the reaction between diethyl trichloro-methyl phosphonate and diphenyl methyl phosphinite". Mor. J. Chem. Vol.4, no.8, pp:830-840.

[6] A. Barhoumi, S. Bakkas and A. El Hajbi. (2018). "Theoretical study of the chemical reactivity of the reaction between trichloromethylphosphine oxide and triethyl phosphite using the DFT B3LYP/6311G(d,p) method". Mor. J. Chem., Vol.6, no.3, pp:414-424, (2018).

[7] H. Gross, H. Seibt, J. Prakt. (1985). "New synthetic method of o,s-thioacetals of formyl phosphonates". Tetrahedron Letters., Vol. 26, no.29, pp: 3479-3482. https://doi.org/10.1016/S00404039(00)98669-6.

[8] V. P. Kukhar, V. I. Pasternak, A. V. Kirsanov, Zh. Obshch. Khim. (2013). "Methylidyne trisphosphonates: Promising C1 building block for the design of phosphate mimetics". Beilstein J Org Chem. Vol.9, pp: 990-1001. https://doi.org/10.3762/bjoc.9.114

[9]Bernd Schäfer (1993). "Eine einfache methode zur herstellung von acceptorsubstituierten $\alpha$ chlormethylenphosphoranen". Vol.49, no.5, pp:1053-1056. https://doi.org/10.1016/s00404020(01)86285-2

[10] G. M. Kosolapoff, J. Amer. Chem. Soc., (1947). "Intermolecular Dehydrations by Means of Phosphorus Pentoxide. I. Preparation of Substituted Acetophenones". Vol. 69, no.7, pp:1651-1652. https://doi.org/10.1021/ja01199a024.

[11]S. Bakkas, M. Julliard, M. Chanon, Tetrahedron., (1987). "Reactivity of triethyl phosphite with tetrachloromethane : electron transfer versus ionic substitution on "positive" halogen". Vol. 43, no.3, pp:501-512. https://doi.org/10.1016/S0040-4020(01)89983-X.

[12] S. Bakkas, A. Mouzdahir, L. Khamliche, M. Julliard, E. Péralez E, M. Chanon., (2000)."Phosphorus, Sulfur and Silicon". Vol. 157, no.1, pp:211-224. https://doi.org/10.1080/10426500008040524

[13] A. Mouzdahir, Thèse de Doctorat de 3ème cycle, Université ChouaibDoukkali, Faculté des Sciences, El Jadida, (1995).

[14]M. J. Frisch, G. W. Trucks, H. B. Schlegel, G. E. Scuseria, M. A. Robb, J. R. Cheeseman, G. Scalmani, V. Barone, B. Mennucci, G. A. Petersson, H. Nakatsuji, M. Caricato, X. Li, H. P. Hratchian, A. F. Izmaylov, J. Bloino, G. Zheng, J. L. Sonnenberg, M. Hada, M. Ehara, K. Toyota, R. Fukuda, J. Hasegawa, M. Ishida, T. Nakajima, Y. Honda, O. Kitao, H. Nakai, T. Vreven, J. A. Montgomery Jr., J. E. Peralta, F. Ogliaro, M. Bearpark, J. J. Heyd, E. Brothers, K. N. Kudin, V. N. Staroverov, R. Kobayashi, J. Normand, K. Raghavachari, A. Rendell, J. C. Burant, S. S. Iyengar, J. Tomasi, M. Cossi, N. Rega, J. M. Millam, M. Klene, J. E. Knox, J. B. Cross, V. Bakken, C. Adamo, J. Jaramillo, R. Gomperts, R. E. Stratmann, O. Yazyev, A. J. Austin, R. Cammi, C. Pomelli, J. W. Ochterski, R. L. Martin, K. Morokuma, V. 
G. Zakrzewski, G. A. Voth, P. Salvador, J. J. Dannenberg, S. Dapprich, A. D. Daniels, Ö. Farkas, J. B. Foresman, J. V Ortiz, J. Cioslowski, and D. J. Fox, (n.d.). (2009).

[15] Civalleri, B., Zicovich-Wilson, C. M., Valenzano, L., \& Ugliengo, P. (2008). "B3LYP augmented with an empirical dispersion term (B3LYP-D*) as applied to molecular crystals". CrystEngComm, Vol.10, no.4, pp: 405-410. https://doi.org/10.1039/b715018k.

[16] Lee, Chengteh; Yang, Weitao; Parr, Robert G. (1988). "Development of the ColleSalvetti correlation-energy formula into a functional of the electron density". Vol.37, no.2, pp:785-789. https://doi.org/10.1103/physrevb.37.785

[17]Mendez, Francisco; Gazquez, Jose L. (1994). "Chemical Reactivity of Enolate Ions: The Local Hard and Soft Acids and Bases Principle Viewpoint". Vol.116, no.20, pp: 92989301. https://doi.org/10.1021/ja00099a055.

[18]Mulliken, R. S. (1955). "Electronic Population Analysis on LCAO [Single Bond] MO Molecular Wave Functions. I". The Journal of Chemical Physics, Vol.23, no.10, pp: 1833-. https://doi.org/10.1063/1.1740588.

[19] Reed, Alan E.; Weinhold, Frank (1983). "Natural bond orbital analysis of near-HartreeFock water dimer". The Journal of Chemical Physics, Vol.78, no.6, pp: 4066-4073. https://doi.org/10.1063/1.445134

[20] Kenichi Fukui., Dennis Caldwell (1977). "Theory of orientation and stereoselection”. J. Springer-Verlag, Vol.11, no.1, pp:185-185. https://doi.org/10.1002/qua.560110116

[21] Jan Fleming, H. G. O. Becker (1978). "Frontier Orbitals and Organic Chemical Reactions". Wiley. Vol.320, no5, pp:879-880. https://doi.org/10.1002/prac.19783200525

[22]Paula Jaramillo; Luis R. Domingo; Eduardo Chamorro; Patricia Pérez (2008). "A further exploration of a nucleophilicity index based on the gas-phase ionization potentials". Vol.865, no.3), pp:68-72. https://doi.org/10.1016/j.theochem.2008.06.022.

[23]Patricia Pérez; Luis R. Domingo; Mario Duque-Noreña; Eduardo Chamorro (2009). “A condensed-to-atom nucleophilicity index. An application to the director effects on the electrophilic aromatic substitutions". Vol.895, no1, pp: 8691. https://doi.org/10.1016/j.theochem.2008.10.014 
Tables

Table 1 Optimized geometric parameters (in Angströms and Degrees) by DFT B3LYP/6$311 \mathrm{G}(\mathrm{d}, \mathrm{p})$ of $\mathrm{CCl}_{3} \mathrm{PO}(\mathrm{OEt})_{2}$ et $\mathrm{CCl}_{3} \mathrm{PO}(\mathrm{Ph})_{2}$.

\begin{tabular}{|c|c|c|c|c|c|c|}
\hline Reagents & \multicolumn{3}{|c|}{$\mathrm{CCl}_{3} \mathrm{PO}(\mathrm{Ph})_{2}$} & \multicolumn{3}{|c|}{$\mathrm{CCl}_{3} \mathrm{PO}(\mathrm{OEt})_{2}$} \\
\hline \multicolumn{2}{|c|}{ Parametres } & Value & $\mathrm{E}(\mathrm{Kcal} / \mathrm{mol})$ & & Value & E(Kcal/mol) \\
\hline \multirow{4}{*}{$\begin{array}{c}\text { Distances and } \\
\text { energies } \\
\text { between bound } \\
\text { atoms }\end{array}$} & $\mathrm{R}(24,25)$ & 1.794 & 473.117 & $\mathrm{R}(1,2)$ & 1.795 & 474.899 \\
\hline & $R(24,26)$ & 1.793 & 472.326 & $\mathrm{R}(1,3)$ & 1.803 & 471.937 \\
\hline & $\mathbf{R}(24,27)$ & 1.809 & 470.456 & $\mathrm{R}(1,22)$ & 1.793 & 476.467 \\
\hline & $\mathbf{R}(1,24)$ & 1.933 & 386.834 & $\mathrm{R}(1,4)$ & 1.889 & 348.644 \\
\hline \multirow{6}{*}{$\begin{array}{l}\text { Valence angles } \\
\text { formed by three } \\
\text { bound atoms }\end{array}$} & $\mathrm{A}(1,24,25)$ & 108.575 & $\ldots \ldots$ & $\mathrm{A}(2,1,3)$ & 109.402 & $\ldots \ldots$ \\
\hline & $\mathrm{A}(1,24,26)$ & 107.817 & & $\mathrm{~A}(2,1,4)$ & 108.750 & \\
\hline & $\mathrm{A}(1,24,27)$ & 112.874 & $\ldots \ldots$ & $\mathrm{A}(2,1,22)$ & 109.825 & $\ldots \ldots$ \\
\hline & $\mathrm{A}(25,24,26)$ & 109.541 & $\ldots \ldots$ & $\mathrm{A}(3,1,4)$ & 107.757 & $\ldots \ldots$ \\
\hline & $\mathrm{A}(25,24,27)$ & 109.400 & $\ldots \ldots$ & $\mathrm{A}(3,1,22)$ & 109.441 & $\ldots \ldots$ \\
\hline & $\mathrm{A}(26,24,27)$ & 108.582 & & $\mathrm{~A}(4,1,22)$ & 111.617 & \\
\hline
\end{tabular}


Table 2 Net loads of the most reactive sites of $\mathrm{CCl}_{3} \mathrm{PO}(\mathrm{OEt})_{2}$ and $\mathrm{CCl}_{3} \mathrm{PO}(\mathrm{Ph})_{2}$ polyhalogenoalkanes calculated by the DFT/B3LYP/6-311G(d,p) method.

\begin{tabular}{|c|c|c|c|c|c|c|c|c|}
\hline Reagents & \multicolumn{4}{|c|}{$\boldsymbol{C C l}_{\mathbf{3}} \boldsymbol{P O}(\boldsymbol{O E t})_{\mathbf{2}}$} & \multicolumn{4}{c|}{$\boldsymbol{C C l}_{\mathbf{3}} \boldsymbol{P O}(\boldsymbol{P h})_{\mathbf{2}}$} \\
\hline Atoms & $\mathbf{C}_{\mathbf{1}}$ & $\mathbf{C l}_{\mathbf{2}}$ & $\mathbf{C l}_{\mathbf{3}}$ & $\mathbf{C l}_{\mathbf{2 2}}$ & $\mathbf{C}_{\mathbf{2 4}}$ & $\mathbf{C l}_{\mathbf{2 5}}$ & $\mathbf{C l}_{\mathbf{2 6}}$ & $\mathbf{C l}_{\mathbf{2}}$ \\
\hline $\begin{array}{c}\text { Net natural } \\
\text { expenses (NPA) }\end{array}$ & -0.494 & 0.045 & 0.031 & 0.049 & -0.469 & 0.048 & 0.050 & 0.014 \\
\hline $\begin{array}{c}\text { Mulliken net } \\
\text { charges (MPA) }\end{array}$ & -0.559 & 0.052 & 0.038 & 0.050 & -0.551 & 0.067 & 0.062 & 0.022 \\
\hline
\end{tabular}

Table 3 The energies (eV) of LUMO, HOMO and the energy gap $\mathrm{E}$ of the polyhalogenoalkanes $\mathrm{CCl}_{3} \mathrm{PO}(\mathrm{OEt})_{2}$ and $\mathrm{CCl}_{3} \mathrm{PO}(\mathrm{Ph})_{2}$ and trivalent phosphorus derivatives 1a, $1 \mathrm{~b}$.

\begin{tabular}{|c|c|c|c|c|c|}
\hline Reagents & $E_{L U M O}$ & $E_{\text {номо }}$ & $E_{1}$ & $E_{2}$ & $E_{3}$ \\
\hline $1 a=P(O E t)_{3}$ & 0.689 & -6.940 & \multirow{4}{*}{5.509} & \multirow{4}{*}{5.159} & \multirow{4}{*}{4.7} \\
\hline $1 b=(P h)_{2} \mathrm{POCH}_{3}$ & -0.899 & -6.131 & & & \\
\hline $2 a=C C l_{3} P O(O E t)_{2}$ & -1.431 & -8.337 & & & \\
\hline $2 b=C C l_{3} P O(P h)_{2}$ & -1.781 & -7.487 & & & \\
\hline
\end{tabular}

$$
\left\{\begin{array}{l}
E_{1}=E_{L U M O(2 a)}-E_{H O M O}(1 a) \\
E_{2}=E_{L U M O(2 b)}-E_{H O M O}(1 a)
\end{array} \text { and } \quad E_{3}=E_{L U M O(2 a)}-E_{H O M O(1 b)}\right.
$$


Table 4 Difference between the two possible combinations HOMO/LUMOof trivalent phosphorus derivatives $\left[(\mathrm{EtO})_{3} \mathrm{P}\right.$ and $\left.(\mathrm{Ph})_{2} \mathrm{POCH}_{3}\right]$ versus polyhaloalkanes $\left[[\mathrm{CCl}]{ }_{-} 3\right.$ $\left[\mathrm{CCl}_{3} \mathrm{PO}(\mathrm{OEt})_{2}\right.$ et $\left.\mathrm{CCl}_{3} \mathrm{PO}(\mathrm{Ph})_{2}\right]$ (the values in $\left.\mathrm{eV}\right)$.

\begin{tabular}{|c|c|c|c|c|c|c|}
\hline Réactifs & $\mathbf{E}_{\text {LUMO }}$ & $\mathbf{E}_{\text {номо }}$ & $\mathbf{E}_{\mathbf{1}}$ & $\mathbf{E}_{\mathbf{2}}$ & $\mathbf{E}_{\mathbf{3}}$ & $\mathbf{E}_{\mathbf{4}}$ \\
\hline $\mathbf{1 a}=(\mathbf{E t O})_{\mathbf{3}} \mathbf{P}$ & 0.689 & -6.940 & $\ldots \ldots$ & $\ldots \ldots$ & $\ldots \ldots$ & $\ldots \ldots$ \\
\hline $\mathbf{1 b}=(\mathbf{P h})_{\mathbf{2}} \mathbf{P O C H} \mathbf{3}_{\mathbf{3}}$ & -0.899 & -6.131 & $\ldots \ldots$ & $\ldots \ldots$ & $\ldots \ldots$ & $\ldots \ldots$ \\
\hline $\mathbf{2 a}=\mathbf{C C l}_{\mathbf{3}} \mathbf{P O}(\mathbf{O E t})_{\mathbf{2}}$ & -1.431 & -8.337 & 5.509 & 9.026 & 4.7 & 7.438 \\
\hline $\mathbf{2 b}=\mathbf{C C l}_{\mathbf{3}} \mathbf{P O}(\mathbf{P h})_{\mathbf{2}}$ & -1.781 & -7.487 & 5.159 & 8.176 & $\ldots \ldots$. & $\ldots \ldots$ \\
\hline
\end{tabular}

$$
\left\{\begin{array} { l } 
{ E _ { 1 } = E _ { L U M O ( 2 a \text { ou } 2 b ) } - E _ { H O M O } ( 1 a ) } \\
{ E _ { 2 } = E _ { L U M O ( 1 a ) } - E _ { H O M O } ( 2 a \text { ou } 2 b ) }
\end{array} \text { and } \left\{\begin{array}{l}
E_{3}=E_{L U M O(2 a)}-E_{H O M O(1 b)} \\
E_{4}=E_{L U M O(1 b)}-E_{H O M O}(2 a)
\end{array}\right.\right.
$$

Table 5 Energies HOMO, LUMO, electronic chemical potential $\mu$, hardness $\eta$, electrophilicity $\omega$ and the overall nucleophilicity $\mathrm{N}$ of the reagents: $(\mathrm{EtO})_{3} \mathrm{P}$, $(\mathrm{Ph})_{2} \mathrm{POCH}_{3}, \mathrm{CCl}_{3} \mathrm{PO}(\mathrm{OEt})_{2}$ and $\mathrm{CCl}_{3} \mathrm{PO}(\mathrm{Ph})_{2}$ (the values in $\mathrm{eV}$ ).

\begin{tabular}{|c|c|c|c|c|c|c|c|c|}
\hline Reagents & $E_{L U M O}$ & $E_{\text {номо }}$ & $\boldsymbol{\mu}$ & $\boldsymbol{\eta}$ & $\boldsymbol{\omega}$ & $\boldsymbol{N}$ & $\Delta \boldsymbol{\omega}_{\mathbf{1}}$ & $\Delta \boldsymbol{\omega}_{\mathbf{2}}$ \\
\hline$(\boldsymbol{E t O})_{3} \boldsymbol{P}$ & 0.689 & -6.940 & -3.125 & 7.629 & 0.640 & 2.428 & $\ldots \ldots$ & $\ldots \ldots$ \\
\hline$(\boldsymbol{P h})_{2} \boldsymbol{P O C H}_{3}$ & -0.899 & -6.131 & -3.515 & 5.232 & 1.180 & 3.237 & $\ldots \ldots$ & $\ldots \ldots$ \\
\hline $\boldsymbol{C C l}_{3} \boldsymbol{P O}(\boldsymbol{O E t})_{2}$ & -1.431 & -8.337 & -4.884 & 6.906 & 1.727 & 1.031 & 1.087 & 0.547 \\
\hline $\boldsymbol{C C l}_{\mathbf{3}} \boldsymbol{P O}(\boldsymbol{P h})_{2}$ & -1.781 & -7.487 & -4.634 & 5.706 & 1.881 & 1.881 & 1.241 & $\ldots \ldots$ \\
\hline
\end{tabular}

$$
\left\{\begin{array}{c}
\Delta \omega_{1}=\omega-\omega\left((E t O)_{3} P\right) \\
\Delta \omega_{2}=\omega\left(C C l_{3} P O(O E t)_{2}\right)-\omega\left((P h)_{2} P O C H_{3}\right)
\end{array}\right.
$$


Table 6 Parr functions calculated using population analysis (PSA) of reagents: $(\text { EtO })_{3} P$, $(\mathrm{Ph})_{2} \mathrm{POCH}_{3}, \mathrm{CCl}_{3} \mathrm{PO}(\mathrm{OEt})_{2}$ and $\mathrm{CCl}_{3} \mathrm{PO}(\mathrm{Ph})_{2}$.

\begin{tabular}{|c|c|c|c|}
\hline Reagents & Site K & $\operatorname{Parr}^{+}(\boldsymbol{r})$ & $\operatorname{Parr}^{-}(\boldsymbol{r})$ \\
\hline \multirow{4}{*}{$(E t O)_{3} P$} & $\mathbf{P}_{1}$ & 0.390 & $\underline{0.399}$ \\
\hline & $\mathbf{O}_{2}$ & -0.014 & 0.026 \\
\hline & $\mathbf{O}_{3}$ & -0.008 & 0.275 \\
\hline & $\mathbf{O}_{4}$ & 0.007 & 0.222 \\
\hline \multirow{2}{*}{$(\mathrm{Ph})_{2} \mathrm{POCH}_{3}$} & $\mathbf{P}$ & 0.175 & $\underline{0.391}$ \\
\hline & $\mathbf{O}$ & 0.005 & 0.111 \\
\hline \multirow{4}{*}{$\mathrm{CCl}_{3} \mathrm{PO}(\mathrm{OEt})_{2}$} & $\mathbf{C}_{1}$ & $\underline{0.296}$ & 0.093 \\
\hline & $\mathbf{C l}_{2}$ & 0.206 & 0.118 \\
\hline & $\mathrm{Cl}_{3}$ & 0.236 & 0.080 \\
\hline & $\mathbf{C l}_{22}$ & 0.197 & 0.200 \\
\hline \multirow{4}{*}{$\mathrm{CCl}_{3} \mathrm{PO}(\mathrm{Ph})_{2}$} & $\mathrm{C}_{24}$ & 0.091 & -0.003 \\
\hline & $\mathrm{Cl}_{25}$ & 0.096 & 0.017 \\
\hline & $\mathrm{Cl}_{26}$ & 0.083 & 0.024 \\
\hline & $\mathbf{C l}_{27}$ & 0.050 & 0.021 \\
\hline
\end{tabular}

Table 7 Calculated values (Kcal/mole) of reaction energy variations $\Delta E_{r}$, reaction enthalpy variations $\Delta H_{r}$ and reaction-free enthalpy variations $\Delta G_{r}$

\begin{tabular}{|c|c|c|c|c|}
\hline Systems & Products & $\Delta \mathbf{H}_{\mathbf{r}}$ & $\Delta \mathbf{E}_{\mathbf{r}}$ & $\Delta \mathbf{G}_{\mathbf{r}}$ \\
\hline \multirow{2}{*}{$\mathrm{P}(\mathrm{OEt})_{3}+\mathrm{CCl}_{3} \mathrm{PO}(\mathrm{OEt})_{2}$} & $\mathbf{P}_{\mathrm{C}(\mathbf{1} \mathbf{a}-\mathbf{2 a})}$ & -24.606 & -25.400 & -21.283 \\
\hline & $\mathbf{P}_{\mathrm{Cl}(\mathbf{1} \mathbf{a}-\mathbf{2 a})}$ & -44.501 & -45.637 & -42.630 \\
\hline \multirow{2}{*}{$\mathrm{P}(\mathrm{OEt})_{3}+\mathrm{CCl}_{3} \mathrm{PO}(\mathrm{Ph})_{2}$} & $\mathbf{P}_{\mathbf{C}(\mathbf{1 a}-2 \mathbf{b})}$ & -25.939 & -26.704 & -22.225 \\
\hline & $\mathbf{P}_{\mathrm{Cl}(\mathbf{1} \mathbf{a}-\mathbf{2 b})}$ & -42.204 & -45.058 & -39.165 \\
\hline \multirow{2}{*}{$\begin{array}{l}(\mathrm{Ph})_{2} \mathrm{POCH}_{3} \\
+\mathrm{CCl}_{3} \mathrm{PO}(\mathrm{OEt})_{2}\end{array}$} & $\mathbf{P}_{\mathrm{C}(1 \mathrm{~b}-2 \mathrm{a})}$ & -14.843 & -15.845 & -12.001 \\
\hline & $\mathbf{P}_{\mathrm{Cl}(\mathbf{1 b}-\mathbf{2 a})}$ & -46.238 & -47.081 & -44.397 \\
\hline
\end{tabular}


Table 8 Total energies $E$, the energy difference of the transition states, the ratio $\mathrm{K}_{\mathrm{Cl}} / \mathrm{K}_{\mathrm{C}}$ and the activation barriers $\Delta \mathrm{E}^{\neq}$reaction of polyhalogenomethane $\mathrm{CCl}_{3} \mathrm{POR}^{\prime \prime}{ }_{2}$ with trivalent phosphorus derivatives calculated by method DFT/B3 LYP/6-311 G(d, p).

\begin{tabular}{|c|c|c|c|c|}
\hline Systemes & $\mathbf{E}(\mathbf{a} \cdot \mathbf{u})$ & $\Delta E^{\neq}(\mathrm{Kcal} / \mathrm{mol})$ & $\mathbf{K}_{\mathbf{C l}} / \mathbf{K}_{\mathbf{C}}$ & $v\left(\mathbf{c m}^{-1}\right)$ \\
\hline $\mathrm{P}(\mathrm{OEt})_{3}+\mathrm{CCl}_{3} \mathrm{PO}(\mathrm{OEt})_{2}$ & -2949.326 & ---- & $1.8410^{14}$ & ---- \\
\hline $\mathbf{T S}_{\mathrm{C}}$ & -2949.253 & 45.808 & ---- & -406.27 \\
\hline $\mathbf{T S}_{\mathrm{Cl}}$ & -2949.284 & 26.355 & ---- & -88.97 \\
\hline $\mathrm{P}(\mathrm{OEt})_{3}+\mathrm{CCl}_{3} \mathrm{PO}(\mathrm{Ph})_{2}$ & $\begin{array}{c}- \\
3103.7103\end{array}$ & ---- & 4.40 & ---- \\
\hline $\mathbf{T S}_{\mathrm{C}}$ & $\begin{array}{c}- \\
3103.6534\end{array}$ & 35.7052 & ---- & -363.23 \\
\hline $\mathbf{T S}_{\mathrm{Cl}}$ & $\begin{array}{c}- \\
3103.6548\end{array}$ & 34.8267 & ---- & -81.07 \\
\hline $\begin{array}{l}(\mathrm{Ph})_{2} \mathrm{POCH}_{3} \\
+\mathrm{CCl}_{3} \mathrm{PO}(\mathrm{OEt})_{2}\end{array}$ & -3064.391 & ---- & $3.3210^{5}$ & ---- \\
\hline $\mathbf{T S}_{\mathrm{C}}$ & -3064.326 & 40.788 & ---- & -347.97 \\
\hline $\mathrm{TS}_{\mathrm{Cl}}$ & -3064.338 & 33.258 & ---- & -98.24 \\
\hline
\end{tabular}


Figures

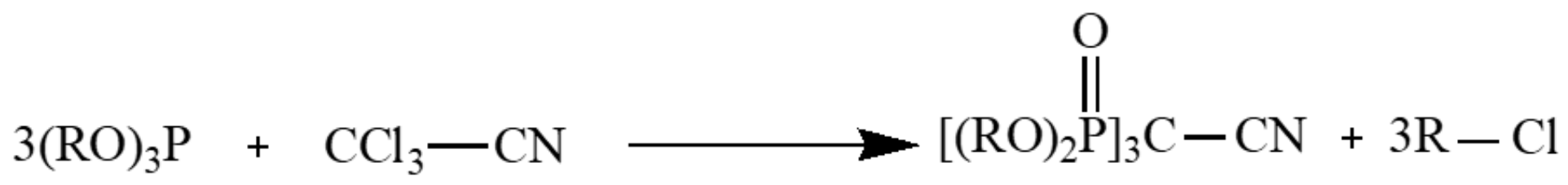

Figure 1

Reaction between trichloro-acetonitrille and trialkylphosphite

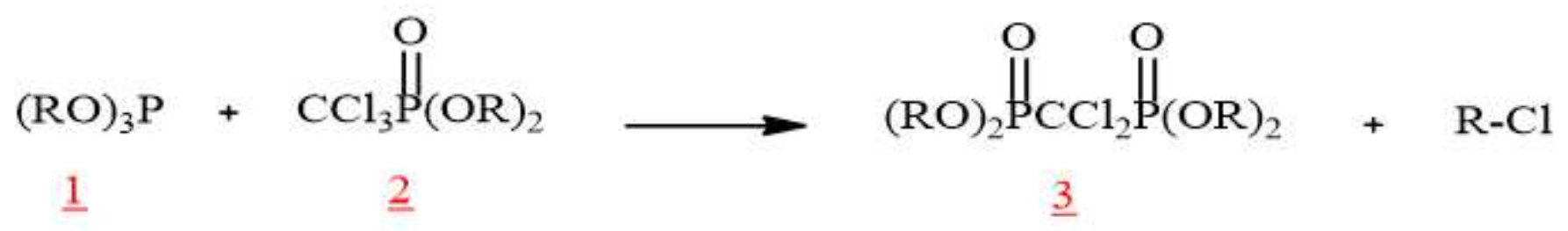

Figure 2

Reaction between trichloro-methyl phosphonate and trialkyl phosphite.

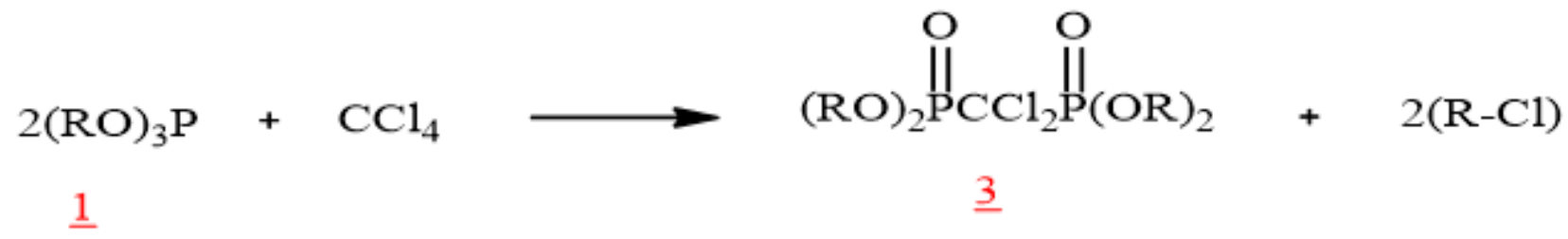

Figure 3

Reaction between tetrachloromethane and trialkyl phosphite. 

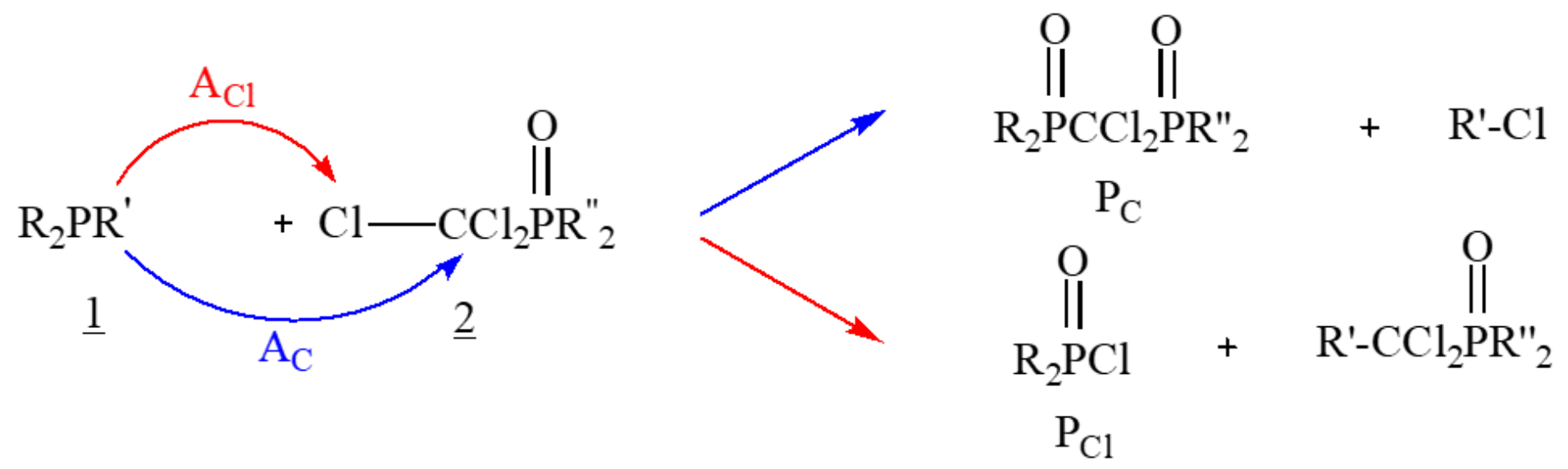

$$
\begin{aligned}
& \underline{1 \mathrm{a}}: \mathrm{R}=\mathrm{R}^{\prime}=\mathrm{OEt} \quad \underline{2 \mathrm{a}}: \mathrm{R}^{\prime \prime}=\mathrm{OEt} \\
& \underline{1 \mathrm{~b}}\left\{\begin{array}{l}
\mathrm{R}=\mathrm{Ph} \\
\mathrm{R}^{\prime}=\mathrm{OCH}_{3}
\end{array} \underline{2 \mathrm{~b}}: \mathrm{R}^{\prime \prime}=\mathrm{Ph}\right.
\end{aligned}
$$

Figure 4

Please see the Supplementry file for the complete figure caption.
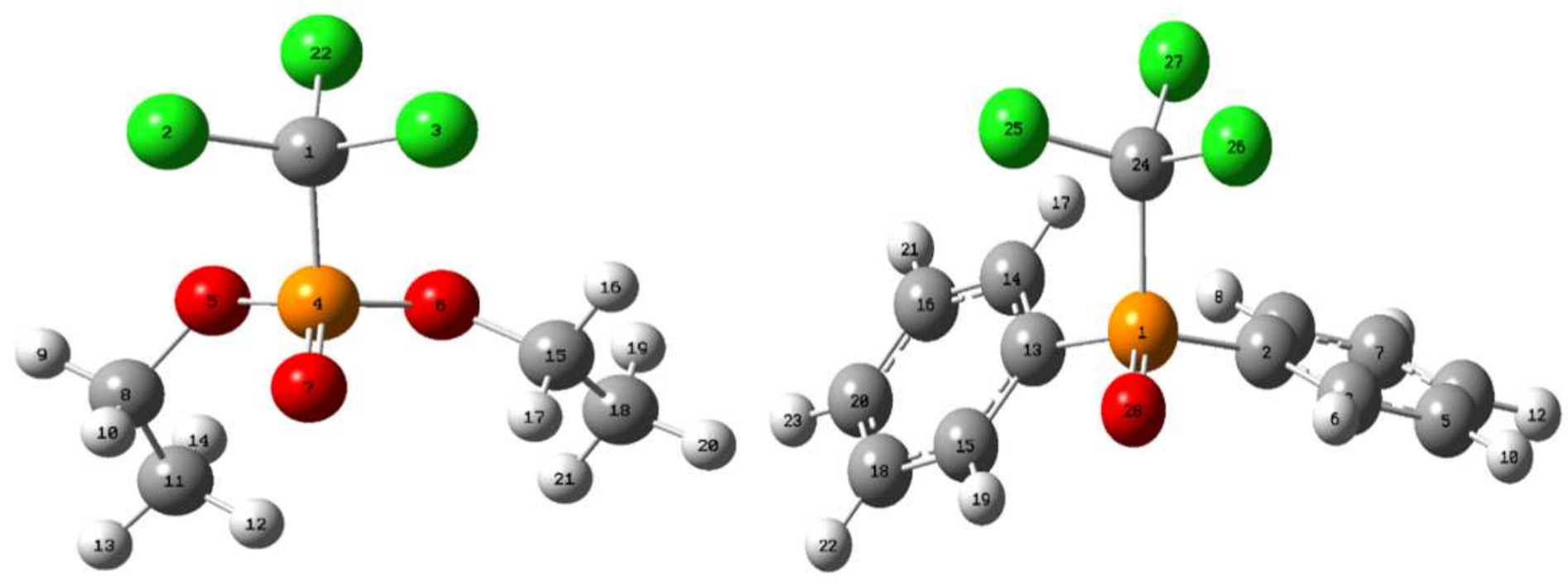

Figure 5

Please see the Supplementry file for the complete figure caption. 


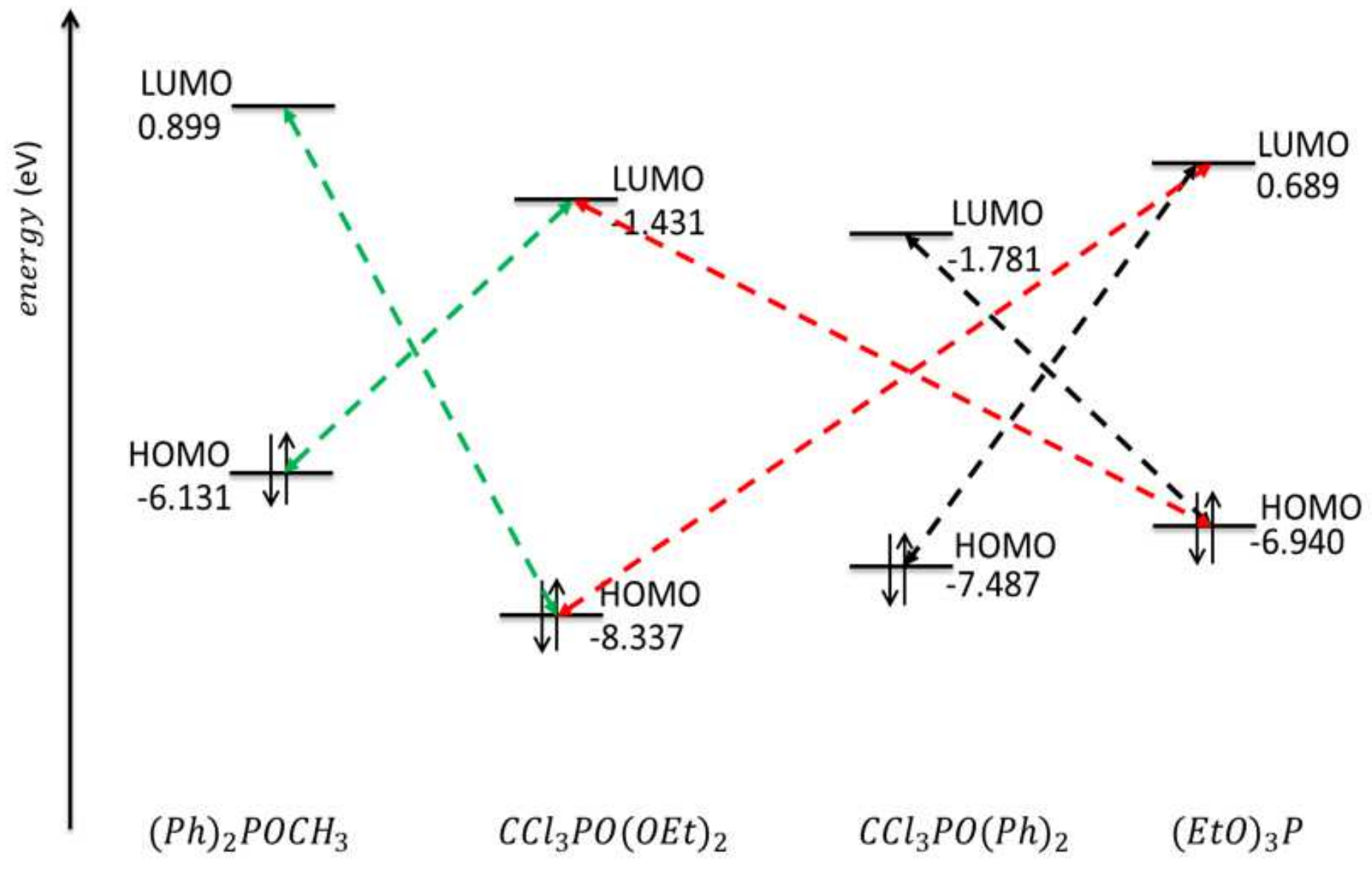

Figure 6

Please see the Supplementry file for the complete figure caption.

LUMO
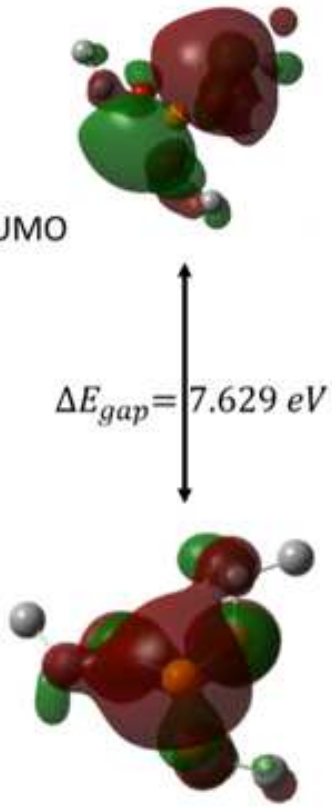

HOMO $(\text { EtO })_{3} P$
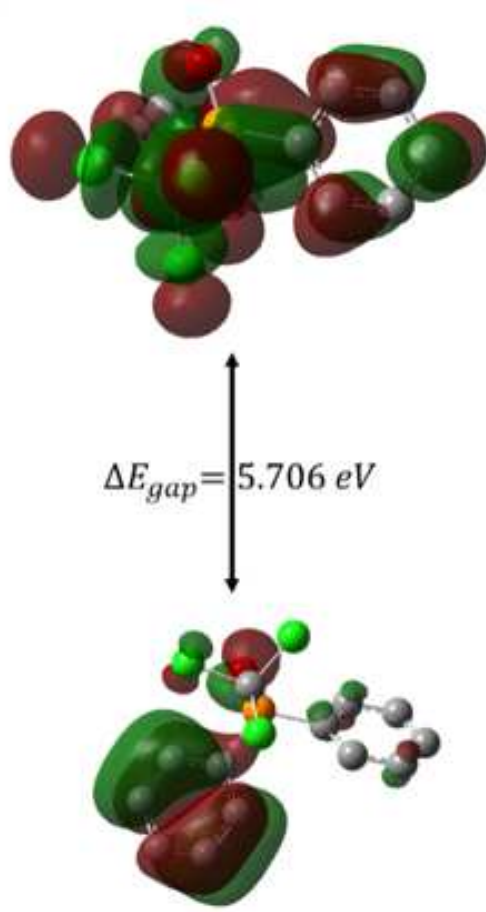

$\mathrm{CCl}_{3} \mathrm{PO}(\mathrm{Ph})_{2}$
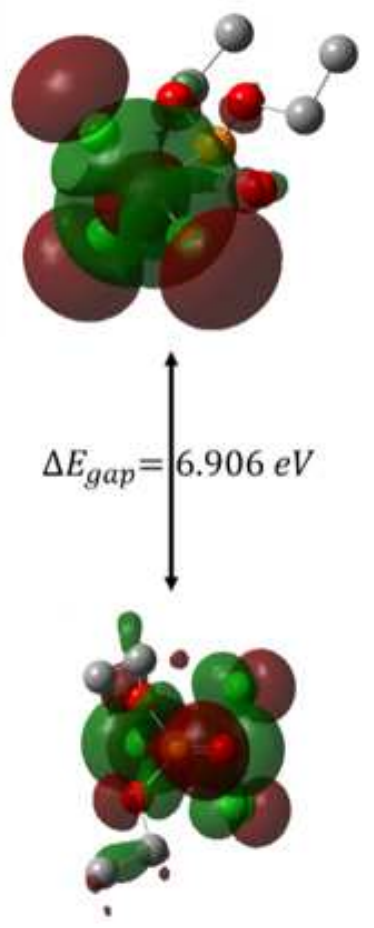

$\mathrm{CCl}_{3} \mathrm{PO}(\mathrm{OEt})_{2}$
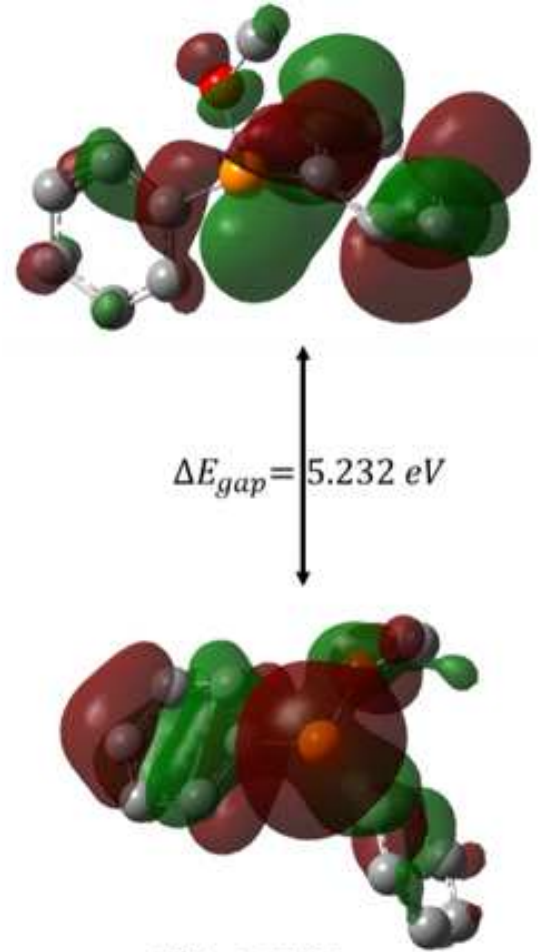

$(\mathrm{Ph})_{2} \mathrm{POCH}_{3}$ 
Figure 7

Energy gap of the orbital boundaries of trivalent phosphorus derivatives and polyhaloalkanes calculated by B3LYP/6-311G(d,p).

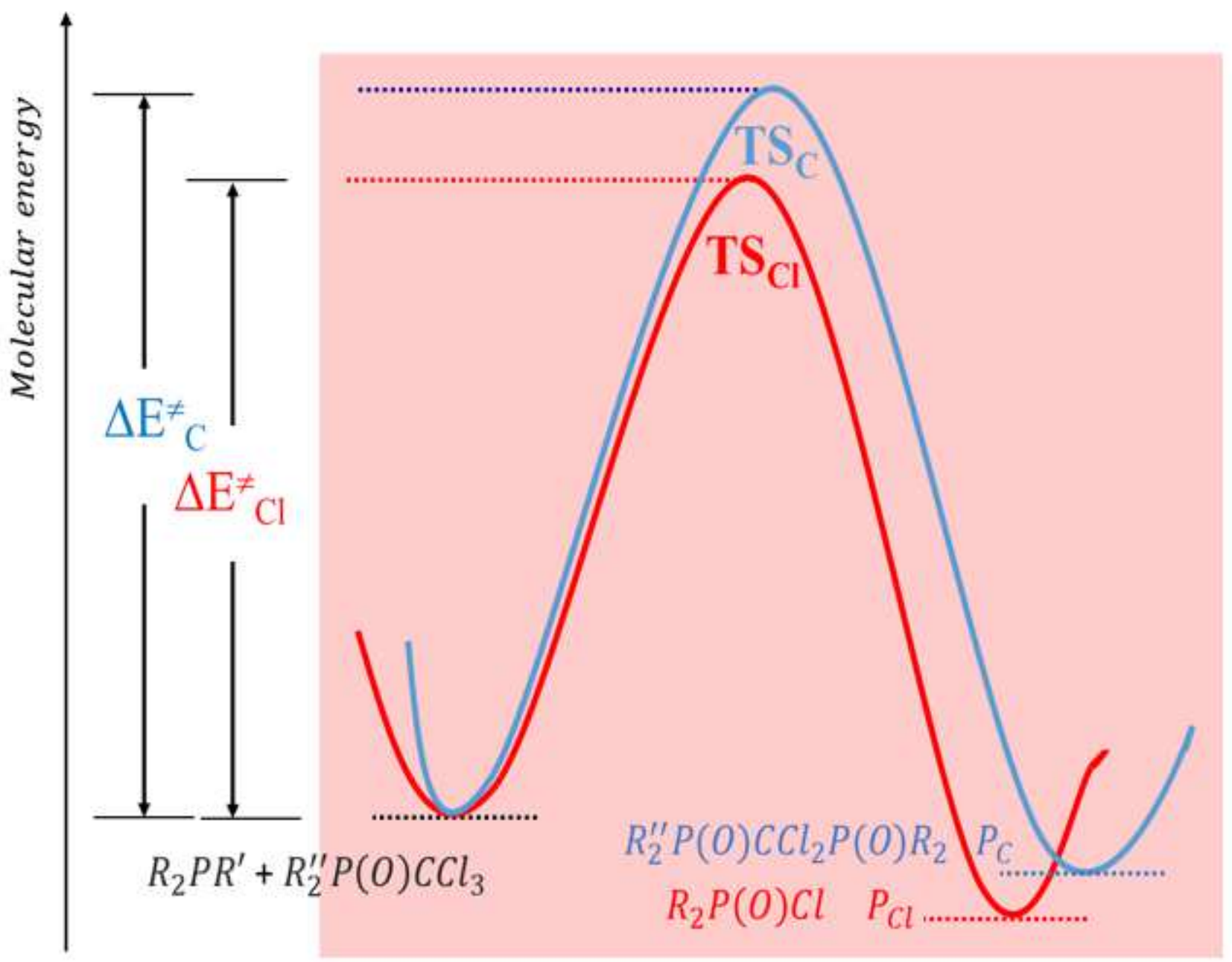

Figure 8

Please see the Supplementry file for the complete figure caption. 


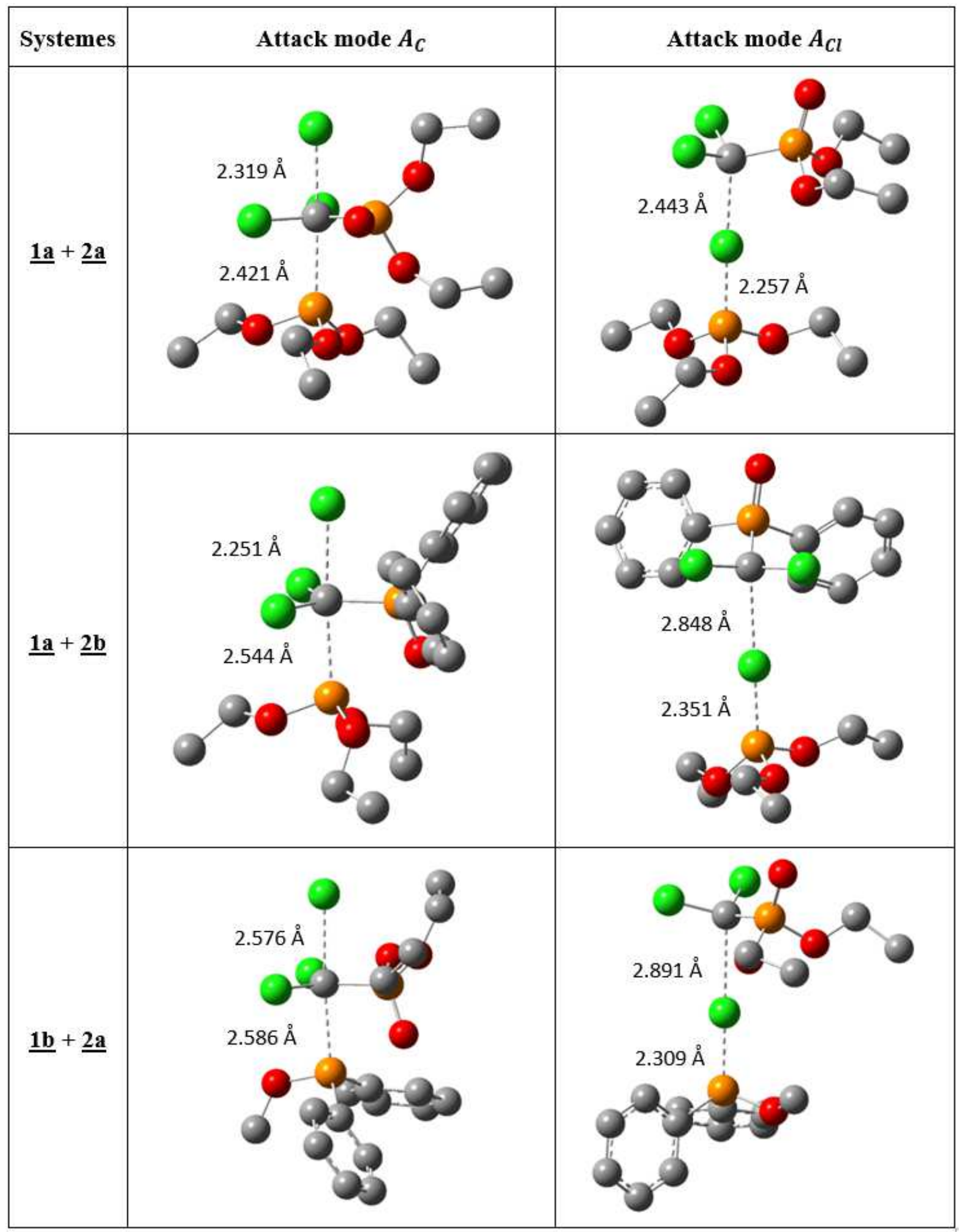

Figure 9

Please see the Supplementry file for the complete figure caption. 
Attack mode $A_{C}$

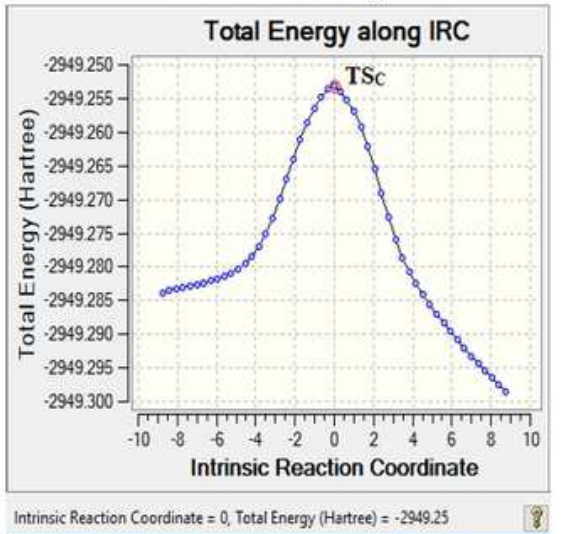

Attack mode $A_{C l}$

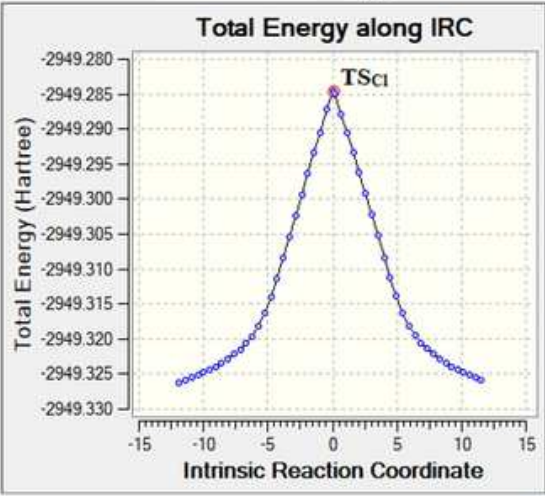

Intrinsic Reaction Coordinate $=0$, Total Energy $($ Hartree $)=-2949.28$

$\mathrm{P}(\mathrm{OEt})_{3}+\mathrm{CCl}_{3} \mathrm{PO}(\mathrm{OEt})_{2}$
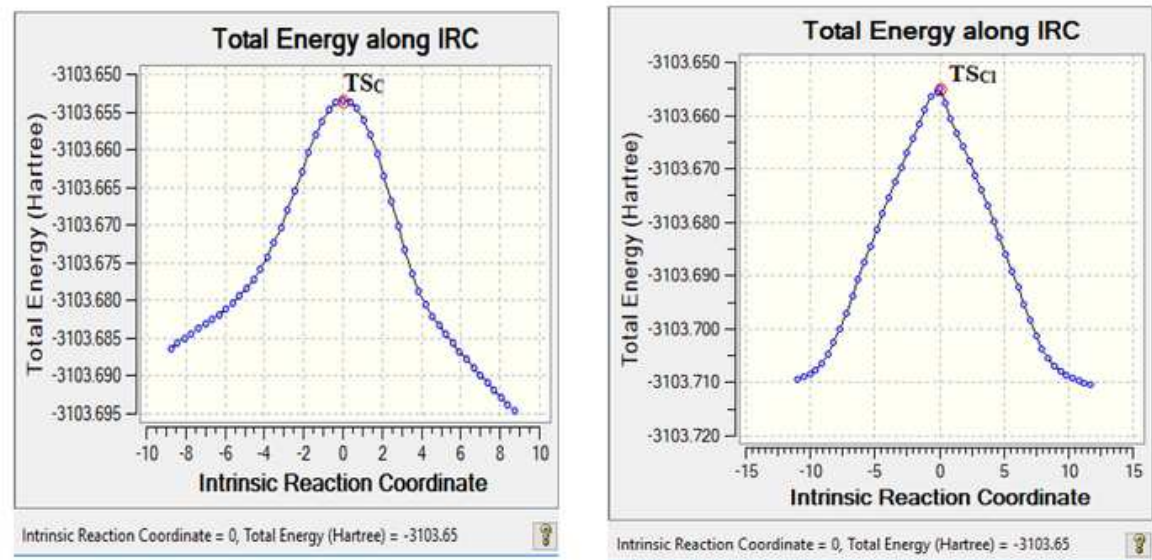

$\mathrm{P}(\mathrm{OEt})_{3}+\mathrm{CCl}_{3} \mathrm{PO}(\mathrm{Ph})_{2}$
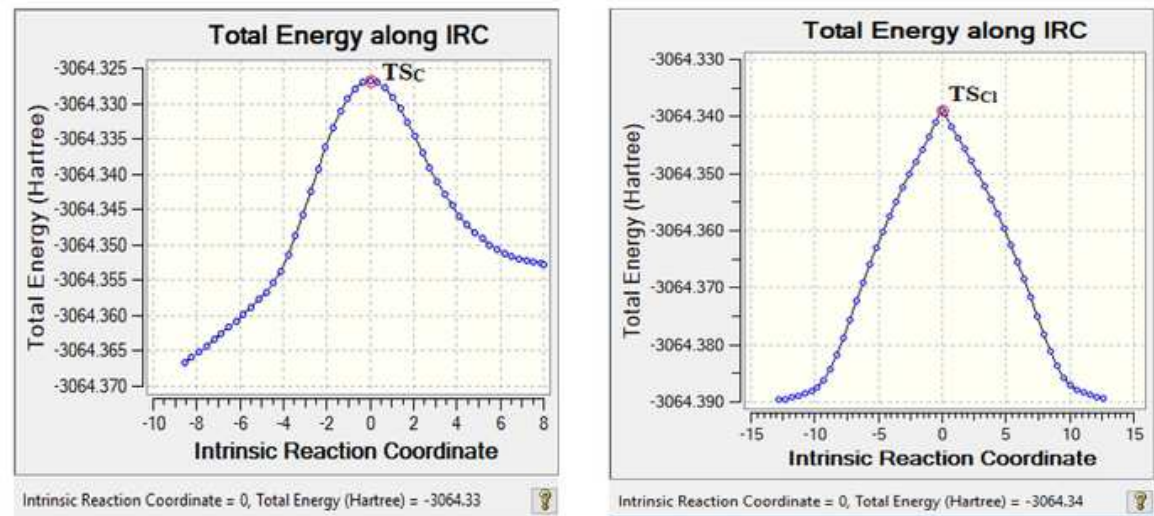

$(\mathrm{Ph})_{2} \mathrm{POCH}_{3}+\mathrm{CCl}_{3} \mathrm{PO}(\mathrm{OEt})_{2}$

\section{Figure 10}

Please see the Supplementry file for the complete figure caption.

\section{Supplementary Files}

This is a list of supplementary files associated with this preprint. Click to download. 
- FigureCaption.docx 